TITLE:

\title{
Investigation of a new natural particleboard adhesive composed of tannin and sucrose
}

$\operatorname{AUTHOR}(S):$

Zhao, Zhongyuan; Umemura, Kenji

\section{CITATION:}

Zhao, Zhongyuan ... [et al]. Investigation of a new natural particleboard adhesive composed of tannin and sucrose. Sustainable humanosphere: bulletin of Research Institute for Sustainable Humanosphere Kyoto University 2014, 10: 9-9

ISSUE DATE:

2014-10-20

URL:

http://hdl.handle.net/2433/196697

RIGHT: 


\title{
Investigation of a new natural particleboard adhesive composed of tannin and sucrose
}

\author{
(Laboratory of Sustainable Materials, RISH, Kyoto University)
}

\author{
Zhongyuan Zhao and Kenji Umemura
}

In the face of dwindling fossil fuel resources and the environmental imperative to reduce emissions associated with petrochemistry, there is strong demand for a wood composite bonding procedure using natural alternatives. Our laboratory carried out a series of the research on the natural adhesives. In this study, particleboards were manufactured with a new material adhesive composed of tannin and sucrose (as Figure 1 shows), and the ratio of tannin and sucrose was 25/75 with the concentration of solution at $40 \mathrm{wt} \%$. The boards were hot-pressed for $10 \mathrm{~min}$. The size of the board was $300 \times 300 \times 90 \mathrm{~mm}$ and the target density was $0.8 \mathrm{~g} / \mathrm{cm} 3$. The effects of the resin contents and hot pressing temperature on the physical properties of the resulting particleboard were investigated.

\section{Materials}

Recycled wood particles were dried in oven at $80^{\circ} \mathrm{C}$ for $12 \mathrm{~h}$. Wattle tannin (Fuji Chemical Industry Co.) and sucrose(Nacalai Tesque, Inc. ) were dried in vacuum oven at $60^{\circ} \mathrm{C}$ for $15 \mathrm{~h}$.

\section{Evaluation of particleboard}

The boards obtained were conditioned for 1 week at $20{ }^{\circ} \mathrm{C}$ and $\mathrm{RH} 60 \%$. The static 3-point bending test, the internal bond strength (IB) test and thickness swelling (TS) test were carried out.

\section{Effects of resin content}

Particleboards were manufactured with the resin content at 10, 15, 20, 30 and $40 \mathrm{wt} \%$. Both MOR and MOE were slightly enhanced with the increase of resin content. The maximum average values of MOR and MOE were 21.2 MPa and 5 $\mathrm{GPa}$, respectively, obtained at $40 \mathrm{wt} \%$ resin content case. The IB strength performance did not change obviously with changes in resin content. The maximum average value was $1.3 \mathrm{MPa}$ at resin content of $30 \mathrm{wt} \%$. The TS value decreased as the resin content increased. The lowest value of TS was $20 \%$ with $40 \mathrm{wt} \%$ resin content. Based on the results above, the optimum resin content was between 30 to $40 \mathrm{wt} \%$.

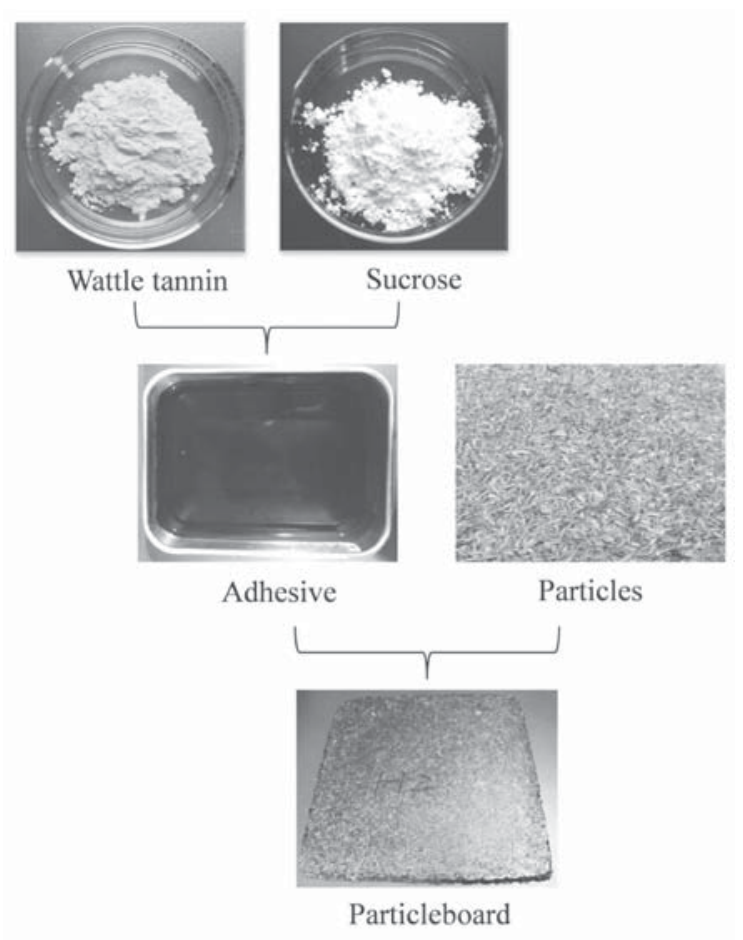

Figure 1. The manufacture of the particleboard bonded with tannin and sucrose

\section{Effects of hot pressing temperature}

Particleboards were manufactured with the hot pressing temperature at 160, 180, 200 and $220^{\circ} \mathrm{C}$. The maximum value of MOR and MOE were 21.9MPa and 4.95GPa, respectively, when the board was bonded with $40 \mathrm{wt} \%$ resin content at $220^{\circ} \mathrm{C}$. The maximum value of IB was $1.6 \mathrm{MPa}$ from the board bonded with $40 \mathrm{wt} \%$ resin content and $220^{\circ} \mathrm{C}$. When the board bonded with 30 and $40 \mathrm{wt} \%$ resin content at $220^{\circ} \mathrm{C}$, the TS values were 9.6 and $7.3 \%$, respectively, this value satisfied requirement of 18 type of JIS A 5908. The results obtained above indicated that, when the hot press temperature increased to $220^{\circ} \mathrm{C}$, the particleboard board bonded with tannin and sucrose performed excellent mechanical properties and water resistance. 